\title{
The effect of dietary nicotine on the allocation of assimilated food to energy metabolism and growth in fourth-instar larvae of the southern armyworm, Spodoptera eridania (Lepidoptera: Noctuidae)
}

\author{
James E. Cresswell, Stewart Z. Merritt, and Michael M. Martin \\ Department of Biology, University of Michigan, Ann Arbor, MI 48109-1048, USA \\ Received July 16, 1991 / Accepted October 23, 1991
}

\begin{abstract}
Summary. Dietary nicotine $(0.5 \%)$, which is a substrate of the PSMO (polysubstrate monooxygenase) detoxification system in the southern armyworm Spodoptera erida nia, has significant negative effects on the weight of food ingested, weight gained, relative growth rate (RGR), and efficiency of conversion of digested food (ECD) by fourthinstar $S$. eridania larvae on a nutrient-rich artificial diet. It has a significant positive effect on the weight of food respired by the larvae. Thus, the detoxification of nicotine by the PSMO system exacts a fitness cost and imposes a metabolic cost on $S$. eridania larvae. In contrast, dietary $\alpha-(+)$-pinene, an inducer of the PSMO system, neither exacts a fitness cost nor imposes a metabolic cost on the larvae. We believe this to be the first study to demonstrate unequivocally that the negative effect of a dietary toxin on net growth efficiency (ECD) in an insect herbivore is due to an increase in the allocation of assimilated food to energy metabolism and not to a decrease in the amount of food assimilated. This study, therefore, supports the hypothesis that detoxification can impose a significant metabolic load on an insect herbivore. Implications of a corroboration of the metabolic load hypothesis are discussed.
\end{abstract}

Key words: Spodoptera eridania - Food utilization Detoxification - Nicotine - Metabolic cost

Assessing the energetic cost of detoxification is an important step in identifying the selective forces that favor host plant specialization in herbivorous insects. If the cost of detoxification makes a significant contribution to the energy budget of an herbivore and the cost of detoxifying structurally diverse allelochemicals is greater than the cost of detoxifying structurally similar compounds, then selection for energy efficiency may favor specialists over generalists (Krieger et al. 1971; Whittaker and Feeny 1971). On the other hand, the metabolic cost of detoxi-

Offprint requests to: M.M. Martin fication is unlikely to be an important factor in the evolution of host plant range if detoxification adds only a negligible amount to the overall energy requirements of an herbivore, and/or the cost is dependent only upon the amount and not upon the diversity of plant allelochemicals that must be detoxified, and/or growth is not energy-limited.

Previous attempts to assess detoxification costs have met with only limited success. On the basis of thermodynamic arguments, Brattsten (1979) concluded that the maintenance and operation of the mixed function oxidase (MFO) or polysubstrate monooxygenase (PSMO) system, which is an important detoxification system in many insects (Ahmad 1986; Ahmad et al. 1986; Brattsten 1988), is a "trivial part of the total energy turnover of an animal the size of a rodent or larger", but "may prove to be energetically costly for smaller animals such as insect herbivores".

Experimental evidence bearing upon the possible metabolic cost of detoxifying, or otherwise processing and excreting, plant allelochemicals by herbivores comes primarily from studies of the effects of dietary chemicals on net growth efficiency (ECD), which is the fraction of assimilated food converted into biomass. A reduction in ECD resulting from the presence of a chemical in the diet has been cited as support for the suggestion that the processing of a potential toxin imposes a metabolic cost on an herbivore (Erickson and Feeny 1974; Schoonhoven and Meerman 1978; Scriber 1979, 1981). If detoxification requires the expenditure of energy, then, it is argued, more assimilated food would have to be allocated to energy metabolism and less would be left over for allocation to growth, resulting in a lower value for ECD. Using similar reasoning, negligible metabolic costs have been ascribed to detoxification processes when ECD has been found to be unaffected by dietary chemicals (Scriber 1978; Neal 1987).

However, a decrease in ECD in response to a dietary chemical may not be a good index of the metabolic cost of processing a potential toxin. ECD is a ratio, not a direct measure of metabolic rate or total metabolic ex- 
penditure; it is the proportion of assimilated food used for growth. Its value is dependent upon not only the amount of assimilate that is allocated to energy metabolism, but also the total amount of food assimilated. Consequently, a decrease in ECD can result either from an increase in total expenditure of energy or a decrease in the amount of food assimilated. Because a dietary chemical could cause a reduction in ECD either by adding a detoxification cost to the energy budget or by acting as a feeding inhibitor and reducing the amount of food assimilated, it follows that a reduction in ECD on a chemical-containing diet is not an infallible indicator of a metabolic cost associated with detoxification. To determine whether a dietary chemical increases metabolic expenditure or reduces food assimilation, it is necessary to determine the absolute amounts of both food allocated to growth and assimilated, not merely their ratio (ECD).

In the present study we have assessed the extent to which nicotine, in the presence and absence of the PSMO-inducer $\alpha-(+)$-pinene, affects growth, food utilization, and energy expenditure in the southern armyworm, Spodoptera eridania (Lepidoptera: Noctuidae). A highly active and inducible PSMO system is largely responsible for the detoxification of nicotine in this species (Brattsten et al. 1977; Brattsten 1986). In order to ensure that we observe only consequences of the operation of the detoxification system and not toxic effects of nicotine that escape detoxification, our experiments have been conducted using low, sub-lethal levels of nicotine $(0.5 \%)$. Our results allow us to determine whether the detoxification of nicotine in $S$. eridania causes an increase in the total amount of food allocated to energy metabolism and/or a decrease in the total amount of food assimilated. We are, therefore, able to distinguish between an effect on ECD due to the imposition of an energy cost and one derived from an effect on consumption or assimilation.

Larvae of S. eridania are broadly polyphagous (Soo Hoo and Fraenkel 1966; Tietz 1972), and are able to detoxify chemicals as diverse as pyridine alkaloids (nicotine), glucosinolates (sinigrin), and cyanogenic glycosides (linamarin) (Brattsten 1986). Our results are compared with those of an earlier study of the effect of nicotine on the tobacco hornworm Manduca sexta, which, in contrast to S. eridania, specializes on nicotine-containing plants (Appel and Martin 1991). We conclude by discussing the implications of the hypothesis that detoxification, or other processes involved in protecting an organism from potentially toxic allelochemicals, impose a metabolic load on an insect herbivore.

\section{Methods and materials}

\section{Insects and artificial diet}

Eggs of $S$. eridania were obtained from the FMC Corporation (Princeton, NJ), where cultures had been maintained on a caseinbased diet for approximately 5 years (W. Fisher, personal communication). Larvae were reared from eggs to the fourth instar $\left(25^{\circ} \mathrm{C}\right.$,
16L:8D) on an artificial diet formulated by combining $21.0 \mathrm{~g}$ of Bio-Serv Diet \#9863 (southern armyworm diet minus casein, methylparaben and agar) with $6.0 \mathrm{~g}$ of casein (US Biochemical Corp), $2.5 \mathrm{~g}$ of agar, and $100 \mathrm{ml}$ of distilled water. All preservatives were omitted from the diet in order to avoid inducing the larval PSMO-enzyme system.

\section{Quantitative nutritional studies}

We used a two-way factorial experimental design with the treatments being presence of $\alpha-(+)$-pinene (a PSMO inducer) and presence of nicotine (a PSMO substrate). From a cohort of individuals that had molted into the fourth instar within 3 hours of each other, we arbitrarily assigned 40 larvae to each of 4 groups: control, $\alpha-(+)$-pinene $(0.25 \% \mathrm{~g} / \mathrm{g}$ dry wt diet, Sigma P3906), nicotine $(0.50 \% \mathrm{~g} / \mathrm{g}$ dry wt diet, Sigma N3876), and $\alpha-(+)$-pinene $(0.25 \%)$ plus nicotine $(0.50 \%)$. The dry weights of the larvae at the beginning of the experiment were calculated from a live weight vs dry weight regression obtained using 20 newly molted fourth-instar larvae that were randomly selected from the same cohort used in the experiment. There were no significant differences in the mean initial weights of the larvae assigned to the four groups (control, $2.88 \mathrm{mg}$; pinene, $2.88 \mathrm{mg}$; nicotine, $2.89 \mathrm{mg}$; pinene plus nicotine, $2.86 \mathrm{mg}$ ).

The larvae were placed individually into $30-\mathrm{ml}$ plastic cups containing a small weighed cube of diet. The cups containing the larvae were placed in an incubator $\left(25^{\circ} \mathrm{C}, 16 \mathrm{~L}: 8 \mathrm{D}\right)$ until the larvae molted to the fifth instar. Since the diets contained no preservatives, it was necessary to change the food every $12 \mathrm{~h}$ to avoid spoilage. Frass and uneaten food were collected and immediately dried in an oven at $75^{\circ} \mathrm{C}$ each time a new weighed cube of diet was provided. To allow for PSMO induction before the introduction of the toxin, larvae in the pinene-plus-nicotine treatment received diet containing only pinene in the first diet cube. All subsequent diet cubes contained the combination of pinene and nicotine. Toward the end of the instar the larvae were checked for molting every half hour so that the duration of the instar could be estimated to within an hour. Larvae were killed by freezing immediately following molting. Uneaten food collected at the different times during the instar was combined, as was frass. Larvae, frass and uneaten food were dried to constant weight in an oven at $75^{\circ} \mathrm{C}$. The dry weight of food supplied was calculated from a wet weight vs dry weight regression obtained by drying additional portions of the artificial diet.

Standard gravimetric techniques (Waldbauer 1968) were used to measure relative growth rate (RGR), relative consumption rate (RCR), approximate digestibility (AD), net growth efficiency or efficiency of conversion of digested food (ECD), and gross growth efficiency or efficiency of conversion of ingested food (ECI). All indices were calculated on a dry weight basis, using the following formulas and definitions: average larval weight $=$ arithmetic mean of initial and final larval weights; weight of food assimilated= weight of food ingested minus weight of frass; weight of food respired $=$ weight of food assimilated minus larval weight gain .

$$
\begin{aligned}
& \mathrm{RGR}=\frac{\text { larval wt gained }}{\text { average larval wt } \times \text { days }} \\
& \mathrm{RCR}=\frac{\text { wt of food ingested }}{\text { average larval wt } \times \text { days }} \\
& \mathrm{AD}=\frac{\text { wt of food assimilated }}{\text { wt of food ingested }} \\
& \mathrm{ECD}=\frac{\text { larval wt gained }}{\text { wt of food assimilated }} \\
& \mathrm{ECI}=\frac{\text { larval wt gained }}{\text { wt of food ingested }}
\end{aligned}
$$


Nutritional indices were obtained for 142 of the 146 larvae successfully reared through the fourth instar. Indices from 7 larvae were discarded as anomalous, because each had an ECI less than 0.13 (mean $\mathrm{ECI}=0.30$, $\mathrm{sd}=0.026$ ). Variation in instar duration, gravimetric measures of consumption, assimilation, growth, and nutritional indices among treatments was analyzed by ANOVA since the requirement for homogeneity of variances was satisfied in all cases.

\section{Respiration rates}

Respiration rates of approximately 20 larvae from each treatment were measured $36-40 \mathrm{~h}$ after molting into the fourth instar. A larva and a cube of fresh diet were weighed and placed in a $30-\mathrm{ml}$ plastic cup whose lid had been adapted for connection to a Gilson respirometer as follows. A $12-\mathrm{mm}$ diameter hole was made in the lid, into which a $20-\mathrm{mm}$ length of Tygon tubing (11/16 inch o.d., $1 / 2$ inch i.d.) was inserted and sealed using a liquid caulking material. The Tygon tubing was connected to the respirometer and sealed with silicone grease, which was also used to seal the cup to the lid. To minimize disturbances to the larvae which might have affected respiration rates (Van Loon 1988), larvae were allowed to equilibrate in the cups for $5 \mathrm{~h}$ before initiating the measurements. Just before connecting the cup to the respirometer, two small microcentrifugation tubes, one containing $0.2 \mathrm{ml}$ of $10 \%$ potassium hydroxide and one containing $0.2 \mathrm{ml}$ of distilled water, were attached to the inside of the rearing cup containing the larva and food using silicone grease as an adhesive. The cups were then attached to a respirometer (Gilson GR 14 or GR 20). Following a 15-min equilibration period, oxygen consumption at $25^{\circ} \mathrm{C}$ was measured over a period of 40 minutes. Separate experiments established that no detectable oxygen consumption was attributable to the presence in the container of food or frass. Linear regressions of respiration rate against larval wet weight were calculated for each treatment, and variation among treatments was analyzed by ANCOVA. An insignificant interaction term between the treatments and the covariate was removed from the final model.

\section{Results}

Gravimetric measurements of growth, food utilization, and energy allocation

$\alpha-(+)$-Pinene, an effective inducer of the PSMO system in S. eridania, has no significant effect on weight of food ingested, larval weight gain, final larval weight, relative growth rate (RGR), relative consumption rate (RCR), approximate digestibility (AD), or efficiency of conversion of ingested food (ECI) (Tables 1 and 2). It has a significant positive effect on efficiency of conversion of digested food (ECD) and significant negative effects on instar duration, weight of food assimilated, and weight of food respired. Thus, the ingestion of $\alpha-(+)$-pinene appears neither to exact a fitness cost in terms of larval weight gain nor to impose a metabolic cost on $S$. eridania larvae. Indeed, not only does the induction of the PSMO system appear not to have resulted in an increase in the total energy expenditure during the fourth instar, but the inclusion of $\alpha-(+)$-pinene in the diet actually reduced the amount of assimilated food allocated to energy metabolism. While we have no data that reveal the mechanistic basis for this reduction in energy expenditure, we suggest that it could be a consequence either of reductions in behavioral activities of larvae on pinene-containing diets
Table 1. Dry matter budgets and nutritional indices (mean and sd) of fourth-instar Spodoptera eridania larvae on a control artificial diet and on diets containing $0.25 \%$ $a$-pinene, $0.5 \%$ nicotine, and $0.25 \%$ pinene plus $0.5 \%$ nicotine. A summary of a twoway analysis of variance is presented in Table 2

\begin{tabular}{|c|c|c|c|c|}
\hline \multirow{2}{*}{$\begin{array}{l}\text { Performance } \\
\text { parameter }\end{array}$} & \multicolumn{4}{|c|}{ Diet } \\
\hline & Control & a-Pinene & Nicotine & $\begin{array}{l}\alpha \text {-Pinene } \\
\text { plus Nicotine }\end{array}$ \\
\hline $\begin{array}{l}\text { Instar duration } \\
\text { (hours) }\end{array}$ & $\begin{array}{l}75 \\
(3.2)\end{array}$ & $\begin{array}{l}75 \\
(3.3)\end{array}$ & $\begin{array}{l}77 \\
(3.8)\end{array}$ & $\begin{array}{l}74 \\
(5.4)\end{array}$ \\
\hline $\begin{array}{l}\text { Food ingested } \\
(\mathrm{mg})\end{array}$ & $\begin{array}{l}42.5 \\
(5.90)\end{array}$ & $\begin{array}{l}40.6 \\
(5.08)\end{array}$ & $\begin{array}{l}38.1 \\
(5.05)\end{array}$ & $\begin{array}{l}38.2 \\
(4.52)\end{array}$ \\
\hline $\begin{array}{l}\text { Food assimilated } \\
(\mathrm{mg})\end{array}$ & $\begin{array}{l}24.5 \\
(2.93)\end{array}$ & $\begin{array}{l}22.9 \\
(3.15)\end{array}$ & $\begin{array}{l}23.1 \\
(2.78)\end{array}$ & $\begin{array}{l}22.6 \\
(2.85)\end{array}$ \\
\hline $\begin{array}{l}\text { Food respired } \\
(\mathrm{mg})\end{array}$ & $\begin{array}{l}11.7 \\
(2.02)\end{array}$ & $\begin{array}{l}10.3 \\
(1.99)\end{array}$ & $\begin{array}{l}12.1 \\
(1.85)\end{array}$ & $\begin{array}{l}11.4 \\
(2.14)\end{array}$ \\
\hline $\begin{array}{l}\text { Larval weight gain } \\
\text { (mg) }\end{array}$ & $\begin{array}{l}12.8 \\
(1.92)\end{array}$ & $\begin{array}{l}12.6 \\
(1.75)\end{array}$ & $\begin{array}{l}11.0 \\
(1.48)\end{array}$ & $\begin{array}{l}11.1 \\
(1.39)\end{array}$ \\
\hline $\begin{array}{l}\text { Final larval weight } \\
\text { (mg) }\end{array}$ & $\begin{array}{l}15.7 \\
(2.19)\end{array}$ & $\begin{array}{l}15.3 \\
(2.32)\end{array}$ & $\begin{array}{l}13.7 \\
(2.05)\end{array}$ & $\begin{array}{l}13.2 \\
(3.12)\end{array}$ \\
\hline $\begin{array}{l}\text { RGR } \\
\text { (mg/day/mg) }\end{array}$ & $\begin{array}{c}0.44 \\
(0.023)\end{array}$ & $\begin{array}{c}0.44 \\
(0.023)\end{array}$ & $\begin{array}{c}0.40 \\
(0.023)\end{array}$ & $\begin{array}{c}0.41 \\
(0.020)\end{array}$ \\
\hline $\begin{array}{l}\text { RCR } \\
\text { (mg/day/mg) }\end{array}$ & $\begin{array}{l}1.45 \\
(0.116)\end{array}$ & $\begin{array}{l}1.42 \\
(0.108)\end{array}$ & $\begin{array}{l}1.41 \\
(0.098)\end{array}$ & $\begin{array}{l}1.41 \\
(0.135)\end{array}$ \\
\hline $\begin{array}{l}\mathrm{AD} \\
(\%)\end{array}$ & $\begin{array}{c}0.58 \\
(0.040)\end{array}$ & $\begin{array}{c}0.56 \\
(0.037)\end{array}$ & $\begin{array}{c}0.61 \\
(0.033)\end{array}$ & $\begin{array}{c}0.59 \\
(0.031)\end{array}$ \\
\hline $\begin{array}{l}\text { ECD } \\
(\%)\end{array}$ & $\begin{array}{l}0.52 \\
(0.060)\end{array}$ & $\begin{array}{l}0.55 \\
(0.043)\end{array}$ & $\begin{array}{c}0.48 \\
(0.042)\end{array}$ & $\begin{array}{l}0.50 \\
(0.051)\end{array}$ \\
\hline $\begin{array}{l}\mathrm{ECI} \\
(\%)\end{array}$ & $\begin{array}{c}0.30 \\
(0.026)\end{array}$ & $\begin{array}{c}0.31 \\
(0.021)\end{array}$ & $\begin{array}{c}0.29 \\
(0.021)\end{array}$ & $\begin{array}{c}0.29 \\
(0.023)\end{array}$ \\
\hline$n$ & 35 & 37 & 33 & 30 \\
\hline
\end{tabular}


Table 2. A summary of two-way analysis of variance of dry matter budgets and nutritional indices for fourth-instar Spodoptera eridania larvae on artificial diets containing $0.25 \% \alpha$-pinene, $0.5 \%$ nicotine, and $0.25 \%$ pinene plus $0.5 \%$ nicotine. Abbreviations: + , positive effect; - , negative effect; ns, not significant; ${ }^{*}, p<0.05$; $* *, p<0.01 ; * * *, p<0.001$

\begin{tabular}{llll}
\hline $\begin{array}{l}\text { Performance } \\
\text { parameter }\end{array}$ & Nicotine & $\alpha$-Pinene & Interaction \\
\hline $\begin{array}{lll}\text { Instar duration } \\
\text { Food ingested }\end{array}$ & $\mathrm{ns}$ & $-\left(^{* *}\right)$ & $\mathrm{ns}$ \\
Food assimilated & $\mathrm{ns}$ & $\mathrm{ns}$ & $\mathrm{ns}$ \\
Food respired & $+\left(^{*}\right)$ & $-\left(^{* *}\right)$ & $\mathrm{ns}$ \\
Larval weight gain & $-\left(^{* *}\right)$ & $\mathrm{ns}$ & $\mathrm{ns}$ \\
Final larval weight & $-\left(^{* * *}\right)$ & $\mathrm{ns}$ & $\mathrm{ns}$ \\
RGR & $-\left({ }^{* *}\right)$ & $\mathrm{ns}$ & $\mathrm{ns}$ \\
RCR & $\mathrm{ns}$ & $\mathrm{ns}$ & $\mathrm{ns}$ \\
AD & $+\left({ }^{*}\right)$ & $\mathrm{ns}$ & $\mathrm{ns}$ \\
ECD & $-\left(^{* * *}\right)$ & $+\left({ }^{*}\right)$ & $\mathrm{ns}$ \\
ECI & $-\left({ }^{*}\right)$ & $\mathrm{ns}$ & $\mathrm{ns}$ \\
\hline
\end{tabular}

or a reduced allocation of energy to maintenance metabolism during the shortened instar, or both.

By contrast, $0.5 \%$ nicotine has detrimental effects on $S$. eridania larvae (Tables 1 and 2). This pyridine alkaloid, which is a substrate of the PSMO system in $S$. eridania, has significant negative effects on the weight of food ingested, weight gained by larvae, and final larval weight, and a significant positive effect on the weight of food respired. Nicotine has a significant negative effect on relative growth rate (RGR), efficiency of conversion of digested food (ECD), and efficiency of conversion of ingested food (ECI), a significant positive effect on approximate digestibility (AD), and no effect on relative consumption rate (RCR) or instar duration. Despite the negative effect of nicotine on the weight of food ingested, nicotine had no significant effect on the weight of food assimilated, as a consequence of the compensating positive effect on assimilation efficiency. Thus, nicotine appears to exact a fitness cost, manifested as decreased larval weight gain, and to impose a metabolic cost on $S$. eridania larvae.

Based upon gravimetric estimates of the amount of food respired, larvae on the nicotine- and nicotine-pluspinene-containing diets allocate 3.4 and $10.7 \%$ more assimilate to energy metabolism than larvae on the control and pinene-containing diets, respectively. This result supports the hypothesis that the detoxification of nicotine, accomplished by the operation of the PSMO-enzyme system, adds a small but significant increment to the metabolic energy expended by the larvae. Since nicotine does not cause a reduction in the amount of food assimilated, this result also supports the hypothesis that the metabolic load associated with detoxification is the cause of the reduced growth of larvae on diets containing this potential toxin.

\section{Respirometric measurements of metabolic rates}

An analysis of covariance of respiration rate against larval wet weight on each diet revealed no significant treatment effects (Table 3). However, the trend in the calculated respiration rates of $80-\mathrm{mg}$ larvae (the average size of the larvae used in the experiments) on the different diets is entirely consistent with the results of our gravimentric measurements of amounts of assimilated food allocated to energy metabolism. Larvae on nicotinecontaining diets have higher respiration rates than larvae on nicotine-free diets, and larvae on pinene-containing diets have respiration rates lower than larvae on pinenefree diets. Apparently closed-system respirometry over short periods of time is too insensitive a method, or variation in respiratory rates among larvae is too great, for this approach to ascribe statistical significance to the differences in the respiration rates detected in our experiments.

\section{Discussion}

To the best of our knowledge, our study of $S$. eridania is the first to demonstrate unequivocally that the negative effect of a dietary toxin on net growth efficiency (ECD) is attributable to an increase in the allocation of assimilated food to energy metabolism and not to a decrease in the size of the assimilate pool. This study, therefore, provides evidence that supports the hypothesis that the detoxification of nicotine by the PSMO system can impose a small but significant metabolic load on an insect herbivore, and leads us to temper the skepticism expressed in an earlier paper (Appel and Martin 1991) concerning the possible importance of detoxification costs in reducing the growth of herbivores on diets containing potential chemical toxins. That study demonstrated that the negative effects of nicotine on the growth
Table 3. Regression of respiration rate $\left(\mu \mathrm{I} \mathrm{O}_{2}\right.$ /hour) against larval fresh weight on a control artificial diet and on diets containing $0.25 \% \alpha$-pinene, $0.5 \%$ nicotine, and $0.25 \% \alpha$-pinene plus $0.5 \%$ nico- tine. An analysis of covariance revealed that neither the slopes nor the intercepts are significantly different

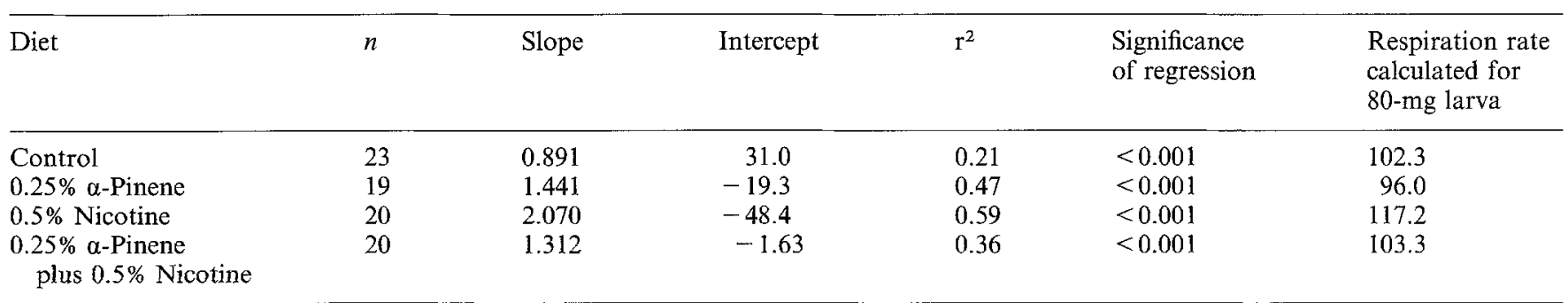


and efficiency of food utilization by the tobacco hornworm, $M$. sexta, are due to reductions in the amount of food consumed and assimilated, not to an increase in the amount of assimilated food committed to energy metabolism.

A possible explanation for the different effects of nicotine on $M$. sexta and $S$. eridania is that the two species use different processes to protect themselves from nicotine toxicity, and these may differ in their energetic costs. The tolerance of nicotine by $M$. sexta larvae derives from rapid excretion and target site insensitivity, whereas the tolerance by $S$. eridania larvae derives from rapid detoxification by the PSMO system (Brattsten 1986). It is possible that the differences between $M$. sexta and $S$. eridania are the result of different degrees of evolutionary adaptation to nicotine-containing plants. $M$. sexta is a specialist on the plant family Solanceae and often exploits nicotine-containing plants, whereas $S$. eridania is a generalist that can, but rarely does, consume nicotine-containing plants. The specialist apparently possesses a mechanism for dealing with this potential toxin that is more energy-efficient than that of the generalist. Additional studies are needed to determine whether the imposition of a metabolic load is a common or rare mechanism mediating the effects of plant allelochemicals on herbivore performance, and to determine whether some toxin-processing systems are more costly to operate than others.

For the diversion of assimilated food to energy metabolism to result in a reduction in growth, growth must be energy-limited. At the present time it is generally believed that the growth of insect herbivores is more likely to be limited by the availability of nitrogen or water than by the availability of energy (Southwood 1973; Slansky and Feeny 1977; Mattson 1980; Scriber 1984; Slansky and Scriber 1985; Schroeder 1986; Martin and Van't Hof 1988). Corroboration of the metabolic load hypothesis indicates that herbivore growth can be energy-limited and that sugar and easily digested carbohydrates, as well as proteins and water, can be important determinants of diet quality. Since our study was conducted using a nutrient-rich artificial diet, it will be necessary to carry out additional studies using diets with different absolute and relative amounts of protein, sugar and water, including some that more closely simulate the composition of natural foliage, in order to define the circumstances under which growth will be energy-limited and under which the metabolic costs of detoxification will result in reduced growth.

Acknowledgements. This research was supported by NSF grant BSR-8904043 to M.M. Martin. We are grateful to William Fisher (FMC Corporation) for providing $S$. eridania eggs.

\section{References}

Ahmad S (1986) Enzymatic adaptations of herbivorous insects and mites to phytochemicals. J Chem Ecol 12:533-560

Ahmad S, Brattsten LB, Mullin CA and Yu SJ (1986) Enzymes involved in the metabolism of plant allelochemicals. In: LB Brattsten and S Ahmad (eds), Molecular Aspects of Insect-Plant Associations, Plenum Press, New York, pp 73-151
Appel HM and Martin MM (1992) The significance of metabolic load in the evolution of host specificity of Manduca sexta (Lepidoptera: Sphingidae). Ecology 73:216-228

Brattsten LB (1979) Biochemical defense mechanisms in herbivores against plant allelochemicals. In: GA Rosenthal and DH Janzen (eds), Herbivores: Their Interaction with Secondary Plant Metabolites, Academic Press, New York, pp 199-270

Brattsten LB (1986) Fate of ingested plant allelochemicals in herbivorous insects. In: LB Brattsten and S Ahmad (eds), Molecular Aspects of Insect-Plant Associations, Plenum Press, New York, pp 211-255

Brattsten LB (1988) Enzymic adaptations in leaf-feeding insects to host-plant allelochemicals. J Chem Ecol 14:1919-1939

Brattsten LB, Wilkinson CF and Eisner T (1977) Herbivore-plant interactions: mixed-function oxidases and secondary plant substances. Science 196: 1349-1352

Erickson JM and Feeny P (1974) Sinigrin: a chemical barrier to the black swallowtail butterfly, Papilio polyxenes. Ecology 55:103-111

Krieger RI, Feeny PP and Wilkinson CF (1971) Detoxification enzymes in the guts of caterpillars: an evolutionary answer to plant defense? Science 171:579-581

Martin MM and Van't Hof HM (1988) The cause of reduced growth of Manduca sexta larvae on a low-water diet: increased metabolic processing costs or nutrient limitation? J Insect Physiol 34:512-525

Mattson WJ (1980) Herbivory in relation to plant nitrogen content. Ann Rev Ecol Syst 11:119--161

Neal JJ (1987) Metabolic costs of mixed-function oxidase induction in Heliothis zea. Entomol Exp Appl 43:175-179

Schoonhoven LM and Meerman J (1978) Metabolic cost of changes in diet and neutralization of alleclochemics. Entomol Exp Appl 24:489-493

Schroeder LA (1986) Protein limitations of a tree feeding Lepidopteran. Entomol Exp Appl 41:115-120

Scriber JM (1978) Cyanogenic glycosides in Lotus corniculatus: their effects upon growth, energy budget, and nitrogen utilization in the southern armyworm, Spodoptera eridania. Oecologia $34: 143-155$

Scriber JM (1979) Post-ingestive utilization of plant biomass and nitrogen by Lepidoptera: legume feeding by the southern armyworm. J New York Entomol Soc 87: 141-153

Scriber JM (1981) Sequential diets, metabolic costs, and growth of Spodoptera eridania (Lepidoptera: Noctuidae) feeding upon dill, lima bean, and cabbage. Oecologia 51:175-180

Scriber JM (1984) Host plant suitability. In: W Bell and RT Carde (eds), Chemical Ecology of Insects, Chapman and Hall, London, pp 159-202

Slansky F and Feeny P (1977) Stabilization of the rate of nitrogen accumulation by larvae of the cabbage butterfly on wild and cultivated food plants. Ecol Monogr 47:209-228

Slansky F and Scriber JM (1985) Food consumption and utilization. In: GA Kerkut and LI Gilbert (eds), Comprehensive Insect Physiology Biochemistry and Pharmacology, vol 4, Pergamon Press, Oxford, pp 87-163

Soo Hoo CF and Fraenkel G (1966) The selection of foodplants in a polyphagous insect, Prodenia eridania (Cramer). J Insect Physiol 12:693-709

Southwood TRE (1973) The insect/plant relationship - an evolutionary perspective. Symp Roy Entomol Soc London 6:3-30

Tietz HM (1972) An Index to the Described Life Histories, Early Stages and Hosts of Macrolepidoptera of the Continental United States and Canada, vol 2, Allyn, Sarasota, p 1041

van Loon JJA (1988) Sensory and nutritional effects of amino acids and phenolic plant compounds on the caterpillars of two Pieris species. Dissertation, Landbouwuniversiteit, Wageningen, The Netherlands

Waldbauer GP (1968) The consumption and utilization of food by insects. Adv Insect Physiol 5:229-288

Whittaker RH and Feeny PP (1971) Allelochemics: chemical interactions between species. Science 171:757-770 